\title{
Compositions of Group IVB Iron Meteorites and Their Parent Melt
}

\author{
ANDREW J. CAMPBELL ${ }^{*}{ }^{1}$ AND MUNIR HUMAYUN ${ }^{2}$ \\ Department of the Geophysical Sciences, \\ The University of Chicago, Chicago, Illinois 60637 USA \\ *email: a-campbell@uchicago.edu \\ ph: (773) 834-1523, fax: (773) 702-9505
}

\footnotetext{
${ }^{1}$ Present address: Department of Geology, University of Maryland, College Park, MD 20742 USA

${ }^{2}$ Present address: National High Magnetic Field Laboratory and Department of Geological Sciences, Florida State University, Tallahassee, FL 32310 USA
}

Submitted to Geochim. Cosmochim. Acta May 4, 2004

Accepted June 14, 2005 
Abstract-The concentrations of P, V, Cr, Fe, Co, Ni, Cu, Ga, Ge, As, Mo, Ru, Rh, Pd, W, Re, Os, Ir, Pt, and Au in the group IVB iron meteorites Cape of Good Hope, Hoba, Skookum, Santa Clara, Tawallah Valley, Tlacotepec, and Warburton Range have been measured by laser ablation inductively coupled plasma mass spectrometry. The data were fitted to a model of fractional crystallization of the IVB parent body core, from which the composition of the parent melt and metal / melt distribution coefficients for each element in the system were determined, for a chosen value of $\mathrm{D}(\mathrm{Ni})$. Relative to $\mathrm{Ni}$ and chondritic abundances, the parent melt was enriched in refractory siderophiles, with greatest enrichment of $5 \times$ chondritic in the most refractory elements, and was strongly volatiledepleted, down to $0.00014 \times$ chondritic in Ge. Comparison to an equilibrium condensation sequence from a gas of solar composition indicates that no single temperature satisfactorily explains the volatility trend in the IVB parent melt; a small $(<1 \%)$ complement of ultrarefractory components added to metal that is volatile-depleted but otherwise has nearly chondritic abundances (for $\mathrm{Fe}, \mathrm{Co}$ and $\mathrm{Ni}$ ) best explains the volatility trend. In addition to this volatility processing, which probably occurred in a nebular setting, there was substantial oxidation of the metal in the IVB parent body, leading to loss of Fe and other moderately siderophile elements such as $\mathrm{Cr}, \mathrm{Ga}$, and $\mathrm{W}$, and producing the high Ni contents that are observed in the IVB irons. By assuming that the entire IVB parent body underwent a similar chemical history as its core, the composition of the silicate that is complementary to the IVB parent melt was also estimated, and appears to be similar to that of the angrite parent. 


\section{INTRODUCTION}

It is believed that the magmatic iron meteorite groups represent fractionally crystallized cores of protoplanetary bodies that formed early in solar system history (Scott, 1972; Scott and Wasson, 1975; Haack and McCoy, 2003). Wasson (1995) estimated that there must be about 70 such differentiated parent bodies represented in the iron meteorite collections. Understanding the chemical and physical properties that produced the variations among the compositions and mineralogical features of iron meteorites, therefore, reveals something about the range of conditions in the solar nebula during the accretion and differentiation of their parent bodies.

This study focusses on the group IVB iron meteorites because, among the major magmatic iron groups, the IVBs have the most extreme compositions in a number of aspects, including the lowest abundances of the volatile elements $\mathrm{Ga}$ and $\mathrm{Ge}$ and, on average, the highest abundances of refractory siderophile elements such as Ir. In some regards the processes that governed the protoplanetary core compositions were acting to an extreme degree in the case of the IVBs, and therefore this group should provide a clear record of those processes.

There are two, very different, perspectives on the origin of the IVB irons. The most widely held view, that they reflect material that condensed at high temperatures in the solar nebula, has been mentioned by several authors (Anders, 1964; Scott, 1972; Haack and McCoy, 2003) but was argued most forcefully by Kelly and Larimer (1977). In the simplest form of this model, the IVB parent body would have been composed principally of hightemperature condensates, probably incorporating material from only the first $<10 \%$ of the condensible material in the nebula (Kelly and Larimer, 1977). Based on a more comprehensive trace element study of the IVB irons, Rasmussen et al. (1984) proposed that the elevated $\mathrm{Ni}$ content resulted from oxidation of $\mathrm{Fe}$ in the parent body, and furthermore, that the elevated Ir/Ni ratio resulted from oxidation even of $\mathrm{Ni}$, indicating a very high 
oxidation state. The volatile depletion in IVB irons was considered by Rasmussen et al. (1984) to be the product of parent body outgassing; in their view nebular processing played no detectable role in the formation of IVB irons.

The present study seeks to find some resolution between these two opposing hypotheses by expanding the number of elements for which compositions are known in a significant number of the IVB iron meteorites. Particularly important to this task is the abundance of Pd, which can be a sensitive indicator of the chemical processes affecting trace element compositions in metal (Campbell et al., 2001). The data are interpreted in terms of a fractional crystallization model of the IVB parent body's core, and the chemical evolution of the IVB core is interpreted from the calculated parent melt. 


\section{EXPERIMENTAL}

The IVB iron meteorites used in this study were: Cape of Good Hope (FMNH \#ME29); Hoba (USNM \#6506 and FMNH \#ME2477); Skookum (AMNH \#273-1; labelled as Klondike (Skookum Gulch)); Santa Clara (FMNH \#ME2859); Tawallah Valley (FMNH \#ME2705); Tlacotepec (FMNH \#ME2159); and Warburton Range (AMNH \#4229-1). Polished surfaces were analyzed for major and trace element analysis by laser ablation inductively coupled plasma mass spectrometry (LA-ICP-MS). The laser ablation system utilized a CETAC LSX-200 laser ablation peripheral with a Finnigan Element ICP mass spectrometer (Campbell and Humayun, 1999a; Campbell et al., 2002; 2003). The standard $5 \times$ objective lens in the LSX-200 has been changed to a $10 \times$ lens, providing greater power density and sensitivity (Campbell et al., 2003). Argon gas is used to carry the ablated material through tygon tubing from the laser ablation chamber to the ICP.

The group IVB irons are ataxites and therefore highly homogeneous. Brief examination of the analyzed surfaces revealed no large inclusions; more detailed petrographic descriptions of these meteorites were provided by Buchwald (1975). Their homogeneity permitted an analytical protocol that forfeits spatial resolution for enhanced sensitivity and precision (Campbell and Humayun, 1999a). A $10 \mathrm{~Hz}$ pulsed laser beam was scanned over the surface of each sample at a rate of $20 \mu \mathrm{m} / \mathrm{s}$. The mass spectrometer recorded intensities from the ablated material at the mass values of interest in a series of 50 mass sweeps. Each line scan was $1 \mathrm{~mm}$ in length; the reported data are the means of five such line scans. Uncertainties include the error on these means in addition to the variation in repeat measurements of the standards. Most of the measured isotopes $\left({ }^{31} \mathrm{P},{ }^{51} \mathrm{~V},{ }^{53} \mathrm{Cr}\right.$, ${ }^{57} \mathrm{Fe}$, ${ }^{59} \mathrm{Co},{ }^{60} \mathrm{Ni},{ }^{75} \mathrm{As},{ }^{95} \mathrm{Mo},{ }^{101} \mathrm{Ru},{ }^{103} \mathrm{Rh},{ }^{105} \mathrm{Pd},{ }^{182} \mathrm{~W},{ }^{185} \mathrm{Re},{ }^{192} \mathrm{Os},{ }^{193} \mathrm{Ir},{ }^{195} \mathrm{Pt}$, and $\left.{ }^{197} \mathrm{Au}\right)$ were recorded in the same set of analyses, using a $50 \mu \mathrm{m}$ diameter laser beam. To improve sensitivity and precision on certain volatile elements, a second set of analyses of ${ }^{62} \mathrm{Ni},{ }^{63} \mathrm{Cu}$,

${ }^{69} \mathrm{Ga}$, and ${ }^{74} \mathrm{Ge}$ was performed using a $150 \mu \mathrm{m}$ diameter beam. Blank subtractions (average 
of 3 measurements with the laser off) were made, and interferences of ${ }^{192} \mathrm{Pt}$ on ${ }^{192} \mathrm{Os}$ were corrected. An interference correction for ${ }^{40} \mathrm{Ar}^{61} \mathrm{Ni}$ on ${ }^{101} \mathrm{Ru}$ was also done, although this was negligible, as were other argide and oxide interferences (Righter et al., 2004). Instrumental sensitivity factors for each isotope were determined by measuring signal intensity from Hoba (USNM \#6506), the group IIA iron meteorite Filomena (USNM \#1334), and the NIST reference steel SRM 1263a, which have known concentrations of the elements of interest (Wasson et al., 1989; Campbell and Humayun, 1999b; Campbell et al., 2002); the values used for calibration are listed in Table 1. Following blank subtraction and correction by the instrumental sensitivity factors, the data were normalized to $100 \%$. Detection limits for each analysis were based on the $3 \sigma$ standard deviation of the three blank measurements. 


\section{RESULTS}

\subsection{LA-ICP-MS Data}

The data for the seven meteorites studied are listed in Table 2. The precision is generally better than $4 \%$, but analyses of elements having low abundance (e.g., Ga, Ge, As) and/or high backgrounds (e.g., P, V, Cr) sometimes show poorer precisions. The only datum below the detection limit was the measurement of As in Cape of Good Hope (Table 2). The entries for Hoba are the means from the two specimens.

The elemental concentrations for each meteorite, normalized to $\mathrm{Ni}$ and $\mathrm{CI}$ chondrite abundances (Anders and Grevesse, 1989), are plotted in Figure 1 in order of each element's volatility in a gas of solar composition (Kelly and Larimer, 1977; Wai and Wasson, 1979). The IVB irons are enriched in the refractory siderophile elements (Re, Os, W, Ir, Ru, Mo, Pt, and $\mathrm{Rh})$ by factors ranging from $(\mathrm{X} / \mathrm{Ni})_{\mathrm{CI}}=1.8$ to $8.0\left(\right.$ where $(\mathrm{X} / \mathrm{Ni})_{\mathrm{CI}}$ is the ratio of element $\mathrm{X}$ to $\mathrm{Ni}$ in the meteorite, normalized to that in $\mathrm{CI}$ chondrites). Nickel, Co, and Pd are in nearly chondritic relative proportions, to within $\pm 25 \%$. Iron is depleted relative to $\mathrm{Ni}$ by a factor of $\sim 0.3$, and the normalized abundances of more volatile elements are progressively lower, reaching $\sim 10^{-4}$ in the case of Ge (Figure 1).

Customarily, trace element abundances in iron meteorites have been plotted against $\mathrm{Ni}$ content for purposes of classification and to identify diagnostic interelement trends, particularly fractional crystallization trends (Scott, 1972; Scott and Wasson, 1975). A weakness of this practice is that $\mathrm{Ni}$ varies little within a magmatic group, so even modest imprecisions in Ni abundance lead to substantial scatter in X-Ni plots. Several iron meteorite researchers (Haack and Scott, 1993; Wasson, 1999; Wasson and Richardson, 2001; Haack and McCoy, 2003) now advocate the use of Au and/or As to visualize interelement trends in iron meteorites, because these two elements partition more strongly than $\mathrm{Ni}$, producing a wider abundance range within the fractional crystallization process. 
Following this recommendation, the new LA-ICP-MS data from this study are plotted against Au in Figure 2.

Most trace elements form well defined trends with respect to Au among the IVB iron meteorites (Figure 2). In addition, a plot of Re, Os, and Pt vs. Ir demonstrates that there are excellent correlations among the refractory PGEs (Figure 3). The data, like those of Rasmussen et al. (1984), indicate that all of the IVB iron meteorites are distributed along compositional trends reminiscent of a fractional crystallization process; the suggestion of Larimer and Rambaldi (1978), that the IVBs should be considered as two genetically distinct subgroups, is not supported by our results.

\subsection{Comparison to Literature Data}

The data from the present study are compared to the neutron activation analysis (NAA) data of Rasmussen et al. (1984) in Figure 2. The LA-ICP-MS data exhibit a slightly larger spread in $\mathrm{Au}$ (59 to $174 \mathrm{ppb}$ ) than the NAA data do (62 to $166 \mathrm{ppb}$ ), but no systematic offset between the two sets of Au measurements is apparent. The agreement is similarly good between the Rasmussen et al. (1984) results and the LA-ICP-MS data for $\mathrm{Cr}, \mathrm{Co}, \mathrm{Ni}$, and As, but minor differences between the data sets can be observed in $\mathrm{Ga}, \mathrm{Ge}$, W, Re, and Ir (Figure 2). The most significant of these discrepancies is in the Ir data, which are $\sim 29 \%$ higher, on average, in the present study than in Rasmussen et al. (1984). This is unexpected because Ir is one of the best-determined trace elements with either technique. The NAA data of Schaudy et al. (1972) are in better agreement, but still $\sim 10 \%$ lower than the present results for Ir (Figure 2). The Ir content of Filomena determined from the calibration data of the present study is $3.55 \pm 0.15 \mathrm{ppm}$, only $5 \%$ higher than the $3.37 \mathrm{ppm}$ value of Wasson et al. (1989).

The agreement between the present results for Pd in the IVB iron meteorites and those determined by thermal ionization mass spectrometry (Kaiser and Wasserburg, 1983; 
Chen and Wasserburg, 1990; 1996) is excellent, as shown in Figure 2. There are detectable differences between the LA-ICP-MS data and the TIMS data for Re and Os (Shen et al., 1996; Smoliar et al., 1996), however (Figure 2). All three studies include measurements of Hoba, which was used as the standard for the LA-ICP-MS analyses. Our Re and Os values for Hoba are 9.5\% and 2.3\% higher, respectively, than those of Shen et al. (1996); for comparison, the Re and Os data of Smoliar et al. (1996) are lower than those of Shen et al. (1996) by 3.4\% and 3.8\%, respectively. These differences are small but significant, and suggest that interlaboratory comparisons between different TIMS laboratories may be similar to, or slightly better than, comparisons between ICP-MS data and TIMS data. Also included in Figure 2 are data from an array of earlier sources using various techniques (Goldberg et al., 1951; Lovering et al., 1957; Wetherill, 1964; Nichiporuk and Brown, 1965; Smales et al., 1967; Herpers et al., 1969; Moore et al., 1969; Schaudy et al., 1972; Buchwald, 1975). The data of Goldberg et al. (1951), Wetherill (1964), and Smales et al. (1967) agree particularly well with the LA-ICP-MS results. The spectrographic data of Nichiporuk and Brown (1965) give uniformly low values for Ru, Rh, Pd, Ir, and Pt.

In general, the results of the present study agree very well with those of earlier analyses, namely, that the IVB iron meteorites are enriched in refractory siderophile elements and strongly depleted in volatile siderophile elements. As Figure 2 indicates, there are a number of elements (e.g., $\mathrm{V}, \mathrm{Cu}, \mathrm{Mo}, \mathrm{Ru}, \mathrm{Rh}$, and $\mathrm{Pt}$ ) for which the present study has greatly expanded and improved the available data set of IVB iron meteorite abundances. In this regard the new results offer the most complete characterization to date of the chemistry of this meteorite group. 


\section{DISCUSSION}

\subsection{Fractional Crystallization of the Group IVB Iron Meteorite Parent Body}

The compositional variation between meteorites within several of the major iron meteorite groups (the so-called 'magmatic' groups) has long been successfully interpreted as the product of fractional crystallization from a molten metallic body, such as the core of a protoplanet (Scott, 1972; Scott and Wasson, 1975). Here we model the fractional crystallization of the measured IVB irons to derive the composition of their parental melt. The fractional crystallization process follows the Raleigh equation:

$$
\mathrm{C}(x)=\mathrm{C}_{0}(x) \mathrm{D}(x)(1-f)^{\mathrm{D}(\mathrm{x})-1}
$$

where $\mathrm{C}(x)$ is the molar concentration of element $x$ in the solid, $\mathrm{C}_{0}$ is the initial concentration in the melt, $\mathrm{D}(x)$ is the solid/melt molar distribution coefficient of element $x$ (assumed constant here, as discussed below), and $f$ is the fraction of melt that has crystallized (constant over all elements for each meteorite). In fitting the data to the set of Eqns. 1 for each element $x$, there are strong tradeoffs between the parameters, and at least two constraints must be applied to the model to obtain a robust solution. An estimate must be made of at least one elemental concentration of the first crystallizing solid, or equivalently of the parental melt. Furthermore, the D value of at least one element must be fixed, usually to a well-determined experimental value.

Solid/melt distribution coefficients in Fe-rich metallic systems are known to be sensitive to the composition of the melt, particularly its 'nonmetal' component such as its $\mathrm{S}$ or P content (Willis and Goldstein, 1982; Jones and Drake, 1983; Chabot et al., 2003). This sensitivity creates some difficulty when modelling fractional crystallization of systems in which the S content is large (Haack and Scott, 1993; Ulff-Møller, 1998; Chabot and Drake, 1999; Wasson, 1999; Wasson and Richardson, 2001; Chabot, 2004), because the changing liquid composition generates profound variations in $\mathrm{D}(x)$ for many elements. In the case of 
the group IVB iron meteorites, it is believed that the $\mathrm{S}$ content of the parental melt was very low (Rasmussen et al., 1984; Willis and Goldstein, 1982; Jones and Drake, 1983; Chabot, 2004); this is manifest in a low frequency of sulfide inclusions, and is believed to be associated with the observed strong depletion of volatile elements. Therefore the $\mathrm{S}$ content of the melt will not increase significantly during most of the crystallization, and changes of $\mathrm{D}(x)$ due to $\mathrm{S}$ content of the melt can be neglected. The few sulfide inclusions that are present in IVB irons may represent trapped melt. Alternatively, up to 0.2 at $\% \mathrm{~S}$ is soluble in Fe metal, and some of the sulfide may be subsolidus precipitation. Regardless, the sulfide content is small, usually estimated on the order of 1 wt\% or less (Rasmussen et al., 1984; Willis and Goldstein, 1982; Chabot, 2004). As discussed below, most trace elements have distribution coefficients in this system that are close to one, and therefore their concentrations in the metal and the melt will not be greatly different. Therefore, the addition of $\sim 1 \%$ melt to the metal will not strongly impact the interpretation of the trace element compositions.

However, the $\mathrm{P}$ content of the IVB system is larger than that of $\mathrm{S}$, and the possible effect of $\mathrm{P}$ on the relevant melting relations and partitioning has not been carefully discussed previously. The measured $\mathrm{P}$ contents of the IVB iron meteorites range from 0.04 to $0.20 \mathrm{wt} \%$ (Table 2); these measurements include not only the $\mathrm{P}$ that is still dissolved in the metal, but also the numerous small phosphide precipitates that are distributed throughout the IVB irons (Buchwald, 1975). Using the partitioning coefficients for P of Willis and Goldstein (1982), the P contents of the IVB irons implies a range of 0.5 to $2.1 \mathrm{wt} \% \mathrm{P}$ in their coexisting liquid. According to the parameterization of Chabot and Drake (2000), this variation in $\mathrm{P}$ content of the melt produces changes of only $\pm 6 \%$ in $\mathrm{D}(\mathrm{Re})$ and $\mathrm{D}(\mathrm{Os})$, and no variation in $\mathrm{D}(\mathrm{Pd})$. This degree of composition dependence of $\mathrm{D}(x)$ is not considered to be important, and is therefore not included in the modelling below. Furthermore, the variation in Ni content is also small (Table 2), and its effect on $\mathrm{D}(x)$ is likewise negligible 
over the observed range (Willis and Goldstein, 1982). Therefore the assumption used here, that $\mathrm{D}(x)$ is constant and independent of $f$, is well justified (Rasmussen et al., 1984).

It can be shown that the slope of an interelement log-log plot is related to the D values of any two elements that are covarying in a fractional crystallization process, where Ds are constant:

$$
\log (\mathrm{C}(x))=(\mathrm{D}(x)-1) /(\mathrm{D}(y)-1) * \log (\mathrm{C}(y))+b
$$

where $b$ is also a constant (Scott, 1972). Therefore, one needs only to specify the $\mathrm{D}(x)$ for a single element $x$ and the Ds for all other elements $y$ are constrained by the manner in which the elements covary (e.g., Figure 2). In most earlier interpretations of iron meteorite crystallization, the practice has been to constrain $\mathrm{D}(\mathrm{Ni})$ and determine other $\mathrm{D}(y)$ from $\log (\mathrm{Ni})-\log (y)$ plots. Based on experimental studies demonstrating the slight incompatibility of $\mathrm{Ni}$, commonly used values for $\mathrm{D}(\mathrm{Ni})$ range from 0.9 to 0.95 , depending on the assumed $\mathrm{S}$ and Ni content. However, it can be seen from Eqn. 2 that the near-unity of $\mathrm{D}(\mathrm{Ni})$ implies that small inaccuracies in the $\mathrm{D}(\mathrm{Ni})$ value used will propagate into large inaccuracies in $\mathrm{D}(\mathrm{Ni})-1$, and hence in $\mathrm{D}(y)$ for other elements. To overcome this problem we have chosen instead to use the experimentally determined value of $\mathrm{D}(\mathrm{P})$ as a constraint to the fractional crystallization model of IVB irons. Phosphorus is a minor element in iron meteorites, but is of sufficiently high abundance that precise $\mathrm{D}(\mathrm{P})$ data are available at appropriate $\mathrm{P}$ contents (Willis and Goldstein, 1982). Phosphorus is a highly incompatible element, with $\mathrm{D}(\mathrm{P})=$ $0.095 \pm 0.003$ for compositions appropriate to the IVB irons (Willis and Goldstein, 1982), and therefore the model is insensitive to modest inaccuracies in the experimentally derived $\mathrm{D}(\mathrm{P})$ value. For example, a $10 \%$ error in $\mathrm{D}(\mathrm{P})$ corresponds to only a $1 \%$ error in $\mathrm{D}(y)-1$. As shown in Figure 4, the chosen value of $\mathrm{D}(\mathrm{P})$, combined with the observed variation between $\mathrm{P}$ and $\mathrm{Ni}$ in the IVB irons, indicates a value of $\mathrm{D}(\mathrm{Ni})=0.924 \pm 0.015$. This value is lower than $\mathrm{D}(\mathrm{Ni})=0.95$ used by Rasmussen et al. (1984), based on an extrapolation of Willis and Goldstein's (1982) data, but it is consistent within the uncertainties of that study. For further comparison, the distribution coefficient that can be calculated from the 
thermodynamic analysis of the Fe-Ni system by Chuang et al. (1986) is $\mathrm{D}(\mathrm{Ni})=$ $0.904 \pm 0.003$ over the range of IVB iron meteorite compositions in Table 2.

We follow the example of Rasmussen et al. (1984) and assume that the initial Ni content of the first crystallizing solid $\left(\mathrm{C}_{\text {initial }}(\mathrm{Ni})=\mathrm{C}_{0}(\mathrm{Ni}) \mathrm{D}(\mathrm{Ni})\right)$ is slightly less than the lowest Ni content observed among the IVB irons. This is equivalent to the assumption that the observed range of compositions in the IVB irons is suitably representative of the core that they sample, and that there is no strong sampling bias. Specifically, we choose a value of $\mathrm{C}_{\text {initial }}(\mathrm{Ni})=0.148$ (equivalent to $15.5 \mathrm{wt} \% \mathrm{Ni}$ ) which, as illustrated in Figure 5a, will yield a range of $f$ values between 0.16 and 0.86 for the IVB irons. To test the sensitivity of our model results to this assumption, we also consider an extreme case in which $\mathrm{C}_{\text {initial }}(\mathrm{Ni})=$ 0.143 (14.9 wt\% Ni), yielding $f \geq 0.5$ for all meteorites (Figure $5 \mathrm{~b}$ ); in this model the IVB irons would be strongly biased toward the later stages of the fractional crystallization process.

Having justified the assumptions of constant $\mathrm{D}(x), \mathrm{D}(\mathrm{P})=0.095$, and $\mathrm{C}_{\text {initial }}(\mathrm{Ni})=$ $15.5 \mathrm{wt} \%$ as discussed above, the measured compositions of IVB iron meteorites in Table 2 were fit to the set of Eqns. 1 by the weighted least-squares method; the results are given in Tables 3 and 4. Vanadium was not modelled, because of the relatively large scatter in those data (Figure 2). As mentioned earlier, the modelled values of $f$ range between 0.16 and 0.86 , indicating an adequate sample of the fractional crystallization process. The sensitivity of the model to the assumed $\mathrm{C}_{\text {initial }}(\mathrm{Ni})$ is demonstrated in Figure 6, in which the Ni- and chondrite-normalized composition of the parent melt from the preferred model $\left(\mathrm{C}_{\text {initial }}(\mathrm{Ni})=\right.$ $15.5 \mathrm{wt} \%)$ is compared to the model of strongly biased sampling $\left(\mathrm{C}_{\text {initial }}(\mathrm{Ni})=14.9 \mathrm{wt} \%\right)$ introduced in Figure 5b. For most elements the difference between the two models is negligibly small, and in general the assumed $\mathrm{C}_{\text {initial }}(\mathrm{Ni})$ has no significant impact on the conclusions of the discussion below. A second, extreme case $\left(\mathrm{C}_{\text {initial }}(\mathrm{Ni})=15.7 \mathrm{wt} \%\right)$, producing $f=0.00$ for the earliest-crystallizing sample, is also shown in Figure 6 , and is hardly distinguishable from our preferred model. 
As shown in Figure 2, the current data set is largely compatible with the earlier NAA data of Rasmussen et al. (1984), and this extends to the fractional crystallization models as well. The differences in partition coefficients derived in the present study from those of Rasmussen et al. (1984), which are also given in Table 3, arise principally from the applied experimental constraints on $\mathrm{D}(x)$. Rasmussen et al. (1984) chose $\mathrm{D}(\mathrm{Ni})=0.95$ in their modelling of the fractional crystallization of the IVB irons, but for reasons given above we chose $\mathrm{D}(\mathrm{P})=0.095$, from which the multielement fit produced $\mathrm{D}(\mathrm{Ni})=0.924$ (Table 3). The two sets of partition coefficients are found to be in excellent agreement if those of Rasmussen et al. (1984) are recalculated using $\mathrm{D}(\mathrm{Ni})=0.924$. Our modelled $f$ values (Table 4) also agree approximately with those of Rasmussen et al. (1984), a consequence of constraining the Ni content of the first-crystallizing solid in a similar manner to that earlier work.

The modelled distribution coefficients are a relatively precise, internally consistent data set that can be usefully compared to experimentally derived values of $\mathrm{D}(x)$ for S-free systems. Experimental partitioning data in metal-melt systems have been compiled and fit to functions of the nonmetal content of the melt by Jones and Malvin (1990) and by Chabot and Jones (2003). Jones and Malvin (1990) presented two different fits for S-rich melts and for P-rich melts, which do not always precisely converge at S- and P-free compositions. Calculated $\mathrm{D}(x)$ from each of these parameterizations of the experimental data are listed in Table 3 for the composition $0 \mathrm{wt} \% \mathrm{~S}, 1.3 \mathrm{wt} \% \mathrm{P}$ appropriate to the IVB parent melt (the $\mathrm{P}$ content used here is an average of the IVB group); for $\mathrm{Cu}$ no published parameterization is available, so a fit to the data from Chabot et al. (2003) was used. In most cases the agreement is excellent, well within the scatter of the experimental data, hence the quality of the fits.

A notable exception is $\mathrm{Cr}$, which is distinctly compatible in the IVB meteorites (see Figure 2, where $\mathrm{Cr}$ is inversely correlated with the incompatible element $\mathrm{Au}$ ) but is incompatible in laboratory experiments and in the parameterization of Jones and Malvin 
(1990). Chabot and Jones (2003) discussed the weakness of such parameterizations in application to chalcophile elements, specifically $\mathrm{Ag}, \mathrm{Cu}$, and $\mathrm{Cr}$; the extension of these parameterizations to the low $\mathrm{S}$ contents suitable to the IVB irons may therefore be unreliable. We note that Rasmussen et al. (1984) also determined $\mathrm{Cr}$ to behave compatibly during crystallization of the IVB parent melt (Figure 2; Table 3). In fact, negative Cr-Ni correlations suggest that $\mathrm{Cr}$ could have been a compatible element during crystallization of other magmatic iron meteorite groups, such as IIAB, IIIAB, and IVA (Scott, 1972); if this is correct, it contradicts the experimental data for $\mathrm{Cr}$ in S-bearing metallic systems. However, it is also conceivable that the correlations in the latter three groups derive from $\mathrm{D}(\mathrm{Cr})$ values that are less than one, but that vary greatly with increasing $S$ content of the melt during crystallization of those iron meteorite systems, as shown for the modelling of $\mathrm{Cu}$ in the IIIAB group (Hongsresawat et al., 2002).

The results of the fractional crystallization modelling (Figure 6) show that the parent melt had a CI chondrite-normalized composition that was largely a function of volatility of the elements. The most refractory elements were enriched in the IVB parent melt by a factor of $\sim 5$ relative to $\mathrm{Ni}$, and this enrichment factor decreases gradually with diminishing condensation temperature. At volatilities lower than $\mathrm{Ni}$, the normalized abundances drop off more rapidly, and the most volatile siderophile elements were present in the parent melt at or below $\sim 0.001 \times$ chondritic levels. Superimposed upon this pronounced volatility trend are notable depletions, particularly in the moderately siderophile elements such as Fe, W, and Cr. These depletions signal redox processes as important contributors, in addition to volatilization, to the parent melt composition for the IVB irons.

\subsection{Oxidation of the IVB Parent Melt}

The degree of oxidation that the IVB parental melt experienced prior to crystallization can be calculated from the depletions in moderately siderophile elements 
relative to highly siderophile elements that have similar volatilities. In particular, much can be learned from considering the relative abundances of $\mathrm{Ni}, \mathrm{Co}, \mathrm{Fe}$, and $\mathrm{Pd}$ shown in Figure 6. First, note that the CI-normalized $\mathrm{Fe} / \mathrm{Pd}$ ratio in the IVB parent melt was $(\mathrm{Fe} / \mathrm{Pd})_{\mathrm{CI}}=$ 0.28. Calculations of equilibrium condensation of metal from a gas of solar composition have shown that $\mathrm{Fe}$ and $\mathrm{Pd}$ have very similar volatilities, and therefore that condensation/evaporation processes should not strongly fractionate Fe from Pd (Kelly and Larimer, 1977; Campbell et al., 2001). However, Pd is much more strongly siderophile than $\mathrm{Fe}$, and we interpret the observed $\mathrm{Fe} / \mathrm{Pd}$ depletions as a consequence of oxidation of the IVB parent melt. Moreover, $(\mathrm{Ni} / \mathrm{Pd})_{\mathrm{CI}}=1.0$ in the inferred parent melt, and $\mathrm{Fe} / \mathrm{Ni}$ is depleted relative to chondritic abundances to a degree similar to $\mathrm{Fe} / \mathrm{Pd}$. This implies that the $\mathrm{Fe} / \mathrm{Ni}$ ratios, and high Ni contents, of the IVB irons was produced by oxidative loss of Fe prior to their fractional crystallization, as previously stated by Rasmussen et al. (1984), and not by incomplete condensation of the metal, as had been advocated by Kelly and Larimer (1977).

However, the oxidation responsible for the $\mathrm{Fe} / \mathrm{Pd}$ and $\mathrm{Fe} / \mathrm{Ni}$ depletions was not severe enough to cause also a Ni depletion, as had been proposed by Rasmussen et al. (1984). If it had been, then the Ni/Pd ratio would not be chondritic, because Pd is more strongly siderophile than Ni. Furthermore, if the oxidation of the IVB precursor had been so extensive that $\mathrm{Ni}$ was significantly oxidized, then Co would be likewise depleted, to an intermediate degree between that of $\mathrm{Fe}$ and $\mathrm{Ni}$; this is not observed (Figure 6).

Rasmussen et al. (1984) appealed to oxidative loss of Ni from the metal to explain the fractionation between $\mathrm{Ni}$ and more highly siderophile elements, such as Ir, in the IVB irons. Because this mechanism is incompatible with the observed, chondritic $\mathrm{Ni} / \mathrm{Pd}$ and $\mathrm{Co} / \mathrm{Ni}$ ratios, we conclude that the fractionation between $\mathrm{Ni}$ and highly refractory siderophiles (Re, Os, Ir, Ru, Pt; Figure 6) is a consequence of the relative volatilities of these elements, as suggested by Anders (1964), Scott (1972), and Kelly and Larimer (1977). These fractionations will be considered further in the following section. 
The oxidation state associated with the observed Fe depletion from the IVB metal can be quantified if the silicate composition that equilibrated with the metal melt is estimated. In Section 4.4 below we make such an estimate, based principally on the assumption that the bulk IVB parent body had a slightly refractory-enriched, devolatilized chondritic composition, and the silicate is complementary to the metal. Anticipating the silicate composition calculated in Section 4.4, we can determine the oxygen fugacity at which the IVB parent melt equilibrated with silicate from

$$
\Delta \mathrm{IW}=2 \log \left(a_{\mathrm{FeO}} / a_{\mathrm{Fe}}\right)
$$

where $\Delta \mathrm{IW}$ is the difference in log units between the $\mathrm{f}\left(\mathrm{O}_{2}\right)$ and the iron-wustite buffer, $a_{\mathrm{FeO}}$ is the activity of $\mathrm{FeO}$ in the silicate, and $a_{\mathrm{Fe}}$ is the activity of $\mathrm{Fe}$ in the metal. Using the thermodynamic data of Chase (1998) and making the approximation of ideal solution in both silicate and metal, we find that metal-silicate equilibrium occurred at $\Delta \mathrm{IW} \approx-1$.

Teshima and Larimer (1983) considered the presence of trace amounts of chromite and daubreelite in Santa Clara and Warburton Range, and its implication on the $\mathrm{f}\left(\mathrm{O}_{2}\right)$ and $\mathrm{f}\left(\mathrm{S}_{2}\right)$ conditions of the IVB parent body. They qualitatively conclude that the IVB parent body was more reducing than most other parent bodies, with the exception of that of the enstatite chondrites. This conclusion appears to be contradicted by the present results, but it is important to recognize that the chromite and daubreelite likely record the conditions during low temperature, subsolidus exsolution. In contrast, the bulk composition of the IVB iron parental melt reflects the conditions during segregation of the metal and silicate phases, which presumably occurred in the molten or partially molten state.

The temperature at which the metal and silicate effectively equilibrated can be estimated from the metal phase equilibria. The fact that the IVB irons are successfully described by fractional crystallization from a S-free melt, as discussed in Section 4.1, suggests that the metal attained a temperature of at least $1760 \mathrm{~K}$; the liquidus in the $\mathrm{Fe}-\mathrm{Ni}$ system at $15.5 \mathrm{wt} \% \mathrm{Ni}$ (Chuang et al., 1986) is $1766 \mathrm{~K}$, and examination of the Fe-P and Ni-P binaries (Massalski et al., 1990) suggests that the effect of $0.4 \mathrm{wt} \% \mathrm{P}$ in the initial melt 
would have lowered the liquidus by $\sim 5 \mathrm{~K}$. The last of the IVB irons to crystallize was Warburton Range, at $18.0 \mathrm{wt} \% \mathrm{Ni}$. In the Fe-Ni system this composition crystallizes at $\sim 1758 \mathrm{~K}$, but the higher $\mathrm{P}$ content of $\sim 2 \mathrm{wt} \%$ in the melt at this stage would have depressed the liquidus by $\sim 60 \mathrm{~K}$. Therefore crystallization of the IVB irons was mostly completed from $1760 \mathrm{~K}$ to $1700 \mathrm{~K}$, though trace amounts of melt could have persisted to the Ni-P binary at 1143 K (Doan and Goldstein, 1970; Massalski et al., 1990). At these high temperatures the silicate portion of the IVB parent body would also have been mostly molten, and one can conclude that metal and silicate segregated and equilibrated within an almost completely molten parent body.

From $1760 \mathrm{~K}$ to $1700 \mathrm{~K}$ the $\mathrm{Mo}-\mathrm{MoO}_{2}$ oxygen fugacity buffer is $\sim 1.4$ log units above IW, and the $\mathrm{W}-\mathrm{WO}_{2}$ buffer is at $\sim \mathrm{IW}+1.3$, using data from Chase (1998). In the absence of strong nonideality, one would expect that the depletions of W and Mo would be less than that of $\mathrm{Fe}$ if the partitioning occurred at these high temperatures, and this is indeed observed (Figure 6). At lower temperatures, the $\mathrm{W}-\mathrm{WO}_{2}$ and $\mathrm{Mo}-\mathrm{MoO}_{2}$ buffers shift below IW, so if metal-silicate equilibration on the IVB parent body had occurred at lower temperatures ( $<1200 \mathrm{~K}$, for example), then one would expect to see larger depletions in $\mathrm{W}$ and Mo than are observed in the IVB irons. The observed $\mathrm{Cr} / \mathrm{Au}$ fractionation, which is stronger than the Fe/Pd fractionation (Figure 6), is also consistent with an $\mathrm{f}\left(\mathrm{O}_{2}\right)$ of IW-1 during metal/silicate segregation on the IVB parent body, because the $\mathrm{Cr}-\mathrm{Cr}_{2} \mathrm{O}_{3}$ buffer is $\sim 4.0 \log$ units below IW at $1760 \mathrm{~K}$ to $1700 \mathrm{~K}$.

\subsection{Nebular Fractionations Affecting the IVB Parent Melt}

In addition to the important effect of oxidation discussed in the previous section, the calculated siderophile element concentrations of the IVB iron meteorite parent melt show a very strong dependence on volatility (Figure 6). The elements are ordered in Figure 6 by

decreasing condensation temperature $\left(\mathrm{T}_{\mathrm{c}}\right)$ into a single-phase $\mathrm{Fe}, \mathrm{Ni}$ alloy from a gas of solar 
composition at $10 \mathrm{~Pa}$ (Palme and Wlotzka, 1976; Kelly and Larimer, 1977; Wai and Wasson, 1979; Sylvester et al., 1990; Campbell et al., 2001; 2003). The most refractory siderophile elements, Re and Os, are enriched relative to Ni and CI chondrites (Anders and Grevesse, 1989) in the preferred estimate of the IVB parent melt composition by a factor of 5.1. With decreasing condensation temperature the other refractory siderophile elements are less enriched, and Co and Pd are at chondritic abundances relative to Ni. Elements having $\mathrm{T}_{\mathrm{c}}$ below that of Fe are increasingly depleted, by orders of magnitude, and the most volatile siderophile measured, $\mathrm{Ge}$, was depleted at a level of $(\mathrm{Ge} / \mathrm{Ni})_{\mathrm{CI}}=1.4 \times 10^{-4}$. Apart from the redox-induced depletions in $\mathrm{W}, \mathrm{Fe}$, and $\mathrm{Cr}$ discussed above, the volatility trend shown in Figure 6 is mostly monotonic. An exception is the subchondritic $\mathrm{Cu} / \mathrm{Ga}$ ratio that is not expected on the basis of the condensation calculations (Wai and Wasson, 1979), but this may be excused because of the uncertainty in activity coefficients used for these elements in the solid Fe-Ni alloy. Alternatively, chalcophile $\mathrm{Cu}$ may be sequestered in the rare troilites in IVB irons.

The slope in normalized abundance that is observed among the refractory siderophiles in the IVB iron meteorites (Figure 1) and their calculated parent melt (Figure 6) is significant. These elements $(\mathrm{Re}, \mathrm{Os}, \mathrm{Ir}, \mathrm{Ru}, \mathrm{Pt})$ are so refractory that they should be completely condensed at temperatures low enough for Fe and Ni to dominate the metallic phase. Under such circumstances one would expect that their relative abundances would be chondritic, not sloping with volatility as observed. Similar refractory siderophile element patterns in Ca,Al-rich refractory inclusions (CAIs) led Palme et al. (1994) and Campbell et al. (2003) to conclude that these objects contained multiple sources of refractory metal, each reflecting a different high-temperature history or characteristic temperature of formation. No single temperature, according to equilibrium calculations of alloy condensation from the solar nebula, can account for the gently sloping patterns; instead, at each specific condensation temperature the relative abundances among these elements tend to be stepped (Palme et al., 1994; Campbell et al., 2003). Furthermore, at temperatures high enough that 
fractionations appear among the refractory PGEs, the PGE contents of the alloy are extremely high, up to $10^{5} \times$ higher than in the IVB iron meteorites. Consequently, we interpret the sloping, moderately enriched refractory siderophile abundances shown in Figures 2 and 6 as indicating the presence of a very small amount of high-temperature metal. Many such grains are likely to have been incorporated into the IVB parent body, and the superposition of them all produced the observed abundance pattern. Depending on the particular composition of the refractory precursor metal grains, they could have composed even less than $0.01 \mathrm{wt} \%$ of the total metal. The balance of the IVB parent body, in this scenario, could have consisted of volatile-depleted but otherwise approximately chondritic composition.

The relative abundances of refractory siderophile elements in the IVB parent melt thus leads to the conclusion that for these elements, at least, it was nebular processing that controlled their composition. No parent body process could reasonably be expected to produce this smoothly varying pattern reflecting very high temperature volatilization (Figure 6). The devolatilization of the parent melt is a different matter. There are no features in the trace element pattern that explicitly exclude the possibility of devolatilization as a consequence of parent body outgassing (Rasmussen et al., 1984). However, the volatile element depletions are quite strong, and it may be difficult to devolatilize an entire parent body to this level of efficiency. Furthermore, it is not necessary to invoke this process, because the refractory siderophiles require that nebular processes are preserved in the chemistry of the IVB iron meteorite compositions, and therefore volatile loss can simply be interpreted as a natural consequence of these high-temperature nebular processes (see Humayun and Cassen, 2000, for a discussion). It should be noted that existing models of nebular volatile element depletion (Humayun and Cassen, 2000) cannot explain the extent of depletion observed for the most volatile-element depleted bodies, such as the Earth, Moon, eucrite parent body and angrite parent body. 
Haack and McCoy (2003) have implied a possible genetic relationship between the IVB irons and condensate metal in $\mathrm{CH} / \mathrm{CB}$ chondrites. The $\mathrm{PGE} / \mathrm{Ni}$ ratios in $\mathrm{CH} / \mathrm{CB}$ metal grains (e.g., Campbell et al., 2001) are not elevated like those of the IVB parent melt (Figure 6), and as Haack and McCoy (2003) note, the nebular temperatures required to generate the IVB parent melt composition are correspondingly higher than for the $\mathrm{CH} / \mathrm{CB}$ metal. The hypothesis of a relationship between these two meteorite groups is neither strengthened nor negated by our results.

\subsection{Silicate Portion of the IVB Parent Body}

It is reasonable to suppose that the silicate portion of the IVB parent body experienced a similar chemical history to that of the core. Namely, it is likely that most of the complementary IVB silicate component had moderate refractory enrichments, strong volatile depletions, and a redox state that is similar to that recorded in the IVB iron meteorites. Therefore some predictions can be made regarding the composition and differentiation of the IVB silicate components.

In Section 4.2 it was determined that the metallic melt from which the IVB iron meteorites crystallized must have experienced at least $1760 \mathrm{~K}$. At this temperature the silicate portion of the parent body would also have been extensively molten, and it is reasonable to infer that metal/silicate segregation into a core and mantle was highly efficient in this mostly molten state. If samples of the silicate fraction of the IVB parent body exist in the meteorite collections, they would be classified as achondrites and would have a very low metal content reflecting this efficient liquid metal/liquid silicate separation.

We estimate the composition of the IVB parent body silicate as a chondritic composition modified by refractory element enrichment, strong volatile element depletion, and extraction of metal having the composition of the IVB iron meteorite parent melt. The results of such a calculation, using CI chondrites as the reference chondritic composition, 
are displayed in Figure 7. In this calculation the refractory lithophiles $\mathrm{Ca}, \mathrm{Al}$, and $\mathrm{Ti}$ were enriched by a factor of 4 relative to $\mathrm{Mg}$ and chondritic abundances, based on the range of refractory siderophile element enrichments observed in the IVB irons (Figure 6). Other refractory lithophiles (Sc, Y, REEs) are expected to have been similarly enriched. Depletions of volatile lithophiles such as $\mathrm{Cr}, \mathrm{Mn}, \mathrm{Na}$, and $\mathrm{K}$ were estimated from the range of depletions of volatile siderophiles in the IVB irons (Figure 6). The bulk silicate composition resulting from these estimates is also given in oxide wt\% in Figure 7. Under the simplifying approximation that the activity of $\mathrm{FeO}$ in the silicate is adequately represented by its mole fraction $\left(\mathrm{X}_{\mathrm{FeO}}=0.20\right)$, the oxygen fugacity can be calculated from Eqn. (3) as approximately IW-1, which was anticipated in Section 4.2 above.

Are there known achondrites having compositions that are compatible with this estimate of the IVB parent body silicate portion? Comparisons of this nature are severely compromised by the fact that the meteorite samples are pieces of silicate bodies that may have been differentiated in complex manners that obscure the bulk parent body compositions. Nevertheless, there is at least one achondrite group that suggests itself as a possible silicate complement to the IVB iron meteorites; this is the angrites. Just as the IVB iron meteorites have the lowest volatile siderophile element contents of any iron meteorite group, the angrites are noted for having lower concentrations of alkalis and other volatile lithophiles than any other basaltic meteorites (Mittlefehldt et al., 1998). Although the petrogenesis of angrites is generally not well understood, one model for their formation invokes a bulk silicate composition of the angrite parent body that is strikingly similar to that estimated above for the IVB parent body. Longhi (1999) parameterized experimental studies of the CMAS+Fe system to evaluate the liquidus phase relations that should be relevant to angrite genesis. He found that the parental source that best explains the range of angrite compositions can be described as an alkali-depleted primitive chondrite (CV) composition, to which a refractory component similar to $\mathrm{Ca}$,Al-rich inclusions has been added, and from which a fraction of approximately 0.4 of the total Fe has been sequestered 
as metal (Longhi, 1999). The angrite parent body core corresponding to such a model would thus be a volatile siderophile-depleted, refractory siderophile-enriched metal from which $\sim 0.6$ of the Fe is lost to oxidation into the silicate, very similar to the description of IVB metal presented above, where 0.72 of the Fe is lost by oxidation. In Figure 7 some angrite whole rock abundances and a composition corresponding to Longhi's (1999) angrite parent body model are compared to our estimate of the IVB parent body silicate. (The potassium depletion for the body is calculated from the $\mathrm{K} / \mathrm{Ba}$ ratio of Angra dos Reis (Humayun and Clayton, 1995)). In detail, there are some differences between the two models, notably the degree of Fe reduction and the nature of the refractory component that is added. Furthermore, the oxidation state under which the angrite silicates last equilibrated (IW+1 to IW+2; Mittlefehldt et al., 1998) is higher than that indicated for metal/silicate segregation by the scenarios presented here and by Longhi (1999). Nevertheless, within the known meteorite collection the angrites are the best available candidates to be representatives of the silicate portion of the IVB parent body. A strong test that could possibly exclude (but not confirm) this association would be a comparison of oxygen isotope compositions of the two meteorite groups. However, no oxygen isotope data are available for the IVB iron meteorites because oxygen-bearing inclusions in them are vanishingly rare (Teshima and Larimer, 1983). 


\section{CONCLUSIONS}

The use of LA-ICP-MS to perform bulk analyses has improved the understanding of group IVB iron meteorite formation by significantly expanding the number of trace elements for which these meteorites have been analyzed in a systematic manner. The precision of these measurements is commonly $<10 \%$ even for volatile siderophile elements such as $\mathrm{Ga}, \mathrm{Ge}$, and Au that are at low abundances (50-200 ppb) in these meteorites. A model of the fractional crystallization of the IVB parental melt has been presented that generated the initial concentrations and metal/melt partition coefficients for siderophile trace elements in that crystallizing system. The partition coefficients derived are very consistent with experimentally-constrained values for S-free metallic systems, with the exception of $\mathrm{D}(\mathrm{Cr})$ highlighting the need for further systematic experimental study of chalcophile element partitioning in these systems.

Based on the results of this study, the following sequence of events is proposed to have produced the IVB iron meteorites:

1) High temperature volatilization/condensation processes in the solar nebula caused fractionations among highly refractory siderophile elements (Mo, Ru, Rh, W, Re, Os, Ir, Pt) in numerous metal grains. These grains represented a range of equilibration temperatures, and may have been highly PGE-rich and Fe,Ni-poor.

2) The refractory metal was accreted into the IVB parent body, along with Fe-Ni metal in which the refractory siderophiles need not have been fractionated from one another, and perhaps not even enriched relative to $\mathrm{Fe}$ and $\mathrm{Ni}$. The Fe-Ni metal was, however, probably volatile-depleted prior to parent body accretion. If the refractory metal component was sufficiently PGE-rich, it may have been only a small fraction, even $<0.01 \mathrm{wt} \%$, of the total metal.

3) The IVB parent body achieved very high internal temperatures of $1760 \mathrm{~K}$ or greater. During melting, coalescence, and homogenization of metal in the parent body, the various 
metal sources were blended, producing a sloped refractory siderophile element pattern in which abundance was a function of volatility, for example $(\mathrm{Os} / \mathrm{Ni})_{\mathrm{CI}}=5$ and $(\mathrm{Pt} / \mathrm{Ni})_{\mathrm{CI}}=2$. Volatile siderophiles were strongly depleted in the metallic melt, with $(\mathrm{Ge} / \mathrm{Ni})_{\mathrm{CI}}=10^{-4}$. 4) The oxygen fugacity during the melting and metal/silicate segregation in the IVB parent body was approximately IW-1, causing several redox-sensitive elements to partition into the silicate. The observed depletions relative to elements of similar volatility, $(\mathrm{Cr} / \mathrm{Au})_{\mathrm{CI}}<(\mathrm{Fe} / \mathrm{Pd})_{\mathrm{CI}}<(\mathrm{W} / \mathrm{Os})_{\mathrm{CI}}<(\mathrm{Mo} / \mathrm{Ir})_{\mathrm{CI}}$, is consistent with the relative positions of the metal-oxide buffers of these elements at high temperatures. The oxidative loss of Fe from the metal was responsible for the observed high Ni contents of the IVB iron meteorites. 5) Fractional crystallization of the melt occurred in the IVB core, mostly over the temperature range $\sim 1760 \mathrm{~K}$ to $\sim 1700 \mathrm{~K}$, and produced the compositional range that is still preserved in the IVB iron meteorites. The melt was virtually S-free but contained a modest $\mathrm{P}$ content ( $0.4 \mathrm{wt} \%$ initially), which had only a very small effect on the trace element partitioning.

The silicate portion of the IVB parent body is presumed to have undergone a similar chemical history, and therefore should exhibit textures and compositions that reflect an extensively molten source that bore modest refractory enrichments, strong volatile depletions, and loss of approximately $28 \%$ of total Fe to the metal. Of the known achondrites, the angrites are the closest match to this postulated IVB silicate source, but this association remains speculative and merits further examination.

Acknowledgments-We are grateful to M. Wadhwa and C. Nuñez of the Field Museum of Natural History and D. Ebel and J. Boesenberg of the American Museum of Natural History for providing specimens of group IVB iron meteorites. We also benefitted from discussions with N. Chabot. The paper benefited from reviews by N. Chabot, H. Haack, D. 
Mittlefehldt and an anonymous reviewer. This work was supported by the NASA Cosmochemistry Program through grant NAG5-13133 to M. H. 


\section{REFERENCES}

Anders E. (1964) Origin, age, and composition of meteorites. Space Sci. Rev. 3, 583-714.

Anders E. and Grevesse N. (1989) Abundances of the elements: Meteoritic and solar. Geochim. Cosmochim. Acta 53, 197-214.

Buchwald V. F. (1975) Handbook of Iron Meteorites. Univ. California Press.

Campbell A. J. and Humayun M. (1999a) Trace element microanalysis in iron meteorites by laser ablation ICPMS. Anal. Chem. 71, 939-946.

Campbell A. J. and Humayun M. (1999b) Microanalysis of platinum group elements in iron meteorites using laser ablation ICP-MS. In Lunar and Planetary Science XXX, Abstract \#1974, Lunar and Planetary Institute, Houston (CD-ROM).

Campbell A. J., Humayun M., Meibom A., Krot A. N., and Keil K. (2001) Origin of zoned metal grains in the QUE94411 chondrite. Geochim. Cosmochim. Acta 65, 163-180.

Campbell A. J., Humayun M., and Weisberg M. K. (2002) Siderophile element constraints on the formation of metal in the metal-rich chondrites Bencubbin, Weatherford, and Gujba. Geochim. Cosmochim. Acta 66, 647-660.

Campbell A. J., Simon S. B., Humayun M., and Grossman L. (2003) Chemical evolution of metal in refractory inclusions in CV3 chondrites. Geochim. Cosmochim. Acta 67, 3119-3134.

Chabot N. L. (2004) Sulfur contents of the parental metallic cores of magmatic iron meteorites. Geochim Cosmochim. Acta 68, 3607-3618.

Chabot N. L. and Drake M. J. (1999) Crystallization of magmatic iron meteorites: The role of mixing in the molten core. Meteorit. Planet. Sci. 34, 235-246.

Chabot N. L. and Drake M. J. (2000) Crystallization of magmatic iron meteorites: The effects of phosphorus and liquid immiscibility. Meteorit. Planet. Sci. 35, 807-816.

Chabot N. L. and Jones J. H. (2003) The parameterization of solid metal-liquid metal partitioning of siderophile elements. Meteorit. Planet. Sci. 38, 1425-1436. 
Chabot N. L., Campbell A. J. , Jones J. H., Humayun M., and Agee C. B. (2003) An experimental test of Henry's Law in solid metal-liquid metal systems with implications for iron meteorites. Meteorit. Planet. Sci. 38, 181-196.

Chase M. W. Jr. (1998) NIST-JANAF Thermochemical Tables, 4th ed. J. Phys. Chem. Ref. Data Monograph No. 9, American Institute of Physics.

Chen J. H. and Wasserburg G. J. (1990) The isotopic composition of Ag in meteorites and the presence of ${ }^{107} \mathrm{Pd}$ in protoplanets. Geochim. Cosmochim. Acta 54, 1729-1743.

Chen J. H. and Wasserburg G. J. (1996) Live ${ }^{107} \mathrm{Pd}$ in the early solar system and implications for planetary evolution. In Earth Processes: Reading the Isotopic Code (eds. A. Basu and S. R. Hart) pp. 1-20. Geophysical Monograph 95, American Geophysical Union.

Chuang Y.-Y., Hsieh K.-C., and Chang Y. A. (1986) A thermodynamic analysis of the phase equilibria of the Fe-Ni system above 1200 K. Metall. Trans. A 17A, 13731380.

Doan A. S. Jr. and Goldstein J. I. (1970) The ternary phase diagram, Fe-Ni-P. Metall. Trans. 1, 1759-1767.

Goldberg E., Uchiyama A., and Brown H. (1951) The distribution of nickel, cobalt, gallium, palladium and gold in iron meteorites. Geochim. Cosmochim. Acta 2, 1-25.

Haack H. and McCoy T. (2003) Iron and stony-iron meteorites. In Treatise on Geochemistry (ed. A. M. Davis), pp. 325-346. Elsevier.

Haack H. and Scott E. R. D. (1993) Chemical fractionations in group IIIAB iron meteorites: Origin by dendritic crystallization of an asteroidal core. Geochim. Cosmochim. Acta 57, 3457-3472.

Herpers U., Herr W., and Wölfle R. (1969) Evaluation of ${ }^{53} \mathrm{Mn}$ by (n, $\left.\gamma\right)$ activation, ${ }^{26} \mathrm{Al}$ and special trace elements in meteorites by $\gamma$-coincidence techniques. In Meteorite Research (editor P. M. Millman) pp. 387-396. D. Reidel. 
Hongsresawat S., Chabot N. L., and Jones J. H. (2002) Modeling the solidification of magmatic iron meteorites using experimental $\mathrm{Cu}$ partitioning. In Lunar and Planetary Science XXXIII, Abstract \#1337, Lunar and Planetary Institute, Houston (CD-ROM).

Humayun M. and Cassen P. (2000) Processes determining the volatile abundances of the meteorites and terrestrial planets. In: R. M. Canup and K. Righter (eds.) Origin of the Earth and Moon, University of Arizona Press, Tucson, pp. 3-23.

Humayun M. and Clayton R. N. (1995) Potassium isotope cosmochemistry: Genetic implications of volatile element depletion. Geochim. Cosmochim. Acta 59, 21312148.

Jones J. H. and Drake M. J. (1983) Experimental investigations of trace element fractionation in iron meteorites, II: The influence of sulfur. Geochim. Cosmochim. Acta 47, 1199-1209.

Jones J. H. and Malvin D. J. (1990) A nonmetal interaction model for the segregation of trace metals during solidification of Fe-Ni-S, Fe-Ni-P, and Fe-Ni-S-P alloys. Metall. Trans. A 21B, 697-706.

Kaiser T. and Wasserburg G. J. (1983) The isotopic composition and concentration of Ag in iron meteorites and the origin of exotic silver. Geochim. Cosmochim. Acta 47, 43-58.

Kelly W. R. and Larimer J. W. (1977) Chemical fractionations in meteorites - VIII. Iron meteorites and the cosmochemical history of the metal phase. Geochim. Cosmochim. Acta 41, 93-111.

Larimer J. W. and Rambaldi E. R. (1978) Trace element chemistry of iron meteorites. Meteoritics 13, 537.

Longhi J. (1999) Phase equilibrium constraints on angrite petrogenesis. Geochim. Cosmochim. Acta 63, 573-585. 
Lovering J. F., Nichiporuk W., Chodos A., and Brown H. (1957) The distribution of cobalt, chromium and copper in iron and stony-iron meteorites in relation to nickel content and structure. Geochim. Cosmochim. Acta 11, 263-278.

Massalski T. B., Okamoto H., Subramanian P. R., and Kacprzak L. (1990) Binary Alloy Phase Diagrams, 2nd Ed. ASM International, Materials Park, Ohio.

Mittlefehldt D. W., McCoy T. J., Goodrich C. A., and Kracher A. (1998) Non-chondritic meteorites from asteroidal bodies. In Planetary Materials (ed. J. J. Papike), Reviews in Mineralogy, Vol. 36. 195 pp. Mineralogical Society of America, Washington.

Moore C. B., Lewis C. F., and Nava D. (1969) Superior analyses of iron meteorites. In Meteorite Research (editor P. M. Millman) pp. 738-748. D. Reidel.

Nichiporuk W. and Brown H. (1965) The distribution of platinum and palladium metals in iron meteorites and in the metal phase of ordinary chondrites. J. Geophys. Res. 70, 459-470.

Palme H. and Wlotzka F. (1976) A metal particle from a Ca,Al-rich inclusion from the meteorite Allende, and the condensation of refractory siderophile elements. Earth Planet. Sci. Lett. 33, 45-60.

Palme H., Hutcheon I. D. and Spettel B. (1994) Composition and origin of refractorymetal-rich assemblages in a Ca,Al-rich Allende inclusion. Geochim. Cosmochim. Acta 58, 495-513.

Rasmussen K. L., Malvin D. J., Buchwald V. F., and Wasson J. T. (1984) Compositional trends and cooling rates of group IVB iron meteorites. Geochim. Cosmochim. Acta 48, 805-813.

Righter K., Campbell A. J., Humayun M., and Hervig R. L. (2004) Partitioning of Ru, Rh, $\mathrm{Pd}, \mathrm{Re}, \mathrm{Ir}$, and Au between Cr-bearing spinel, olivine, pyroxene and silicate melts. Geochim. Cosmochim. Acta 68, 867-880. 
Schaudy R., Wasson J. T., and Buchwald V. F. (1972) The chemical classification of iron meteorites. VI. A reinvestigation of irons with Ge concentrations lower than $1 \mathrm{ppm}$. Icarus 17, 174-192.

Scott E. R. D. (1972) Chemical fractionation in iron meteorites and its interpretation. Geochim. Cosmochim. Acta 36, 1205-1236.

Scott E. R. D. and Wasson J. T. (1975) Classification and properties of iron meteorites. Rev. Geophys. Space Phys. 13, 527-546.

Shen J. J., Papanastassiou D. A., and Wasserburg G. J. (1996) Precise Re-Os determinations and systematics of iron meteorites. Geochim. Cosmochim. Acta $\mathbf{6 0}$, 2887-2900.

Smales A. A., Mapper D., and Fouché K. F. (1967) The distribution of some trace elements in iron meteorites, as determined by neutron activation. Geochim. Cosmochim. Acta 31, 673-720.

Smoliar M. I., Walker R. J., and Morgon J. W. (1996) Re-Os ages of group IIA, IIIA, IVA, and IVB iron meteorites. Science 271, 1099-1102.

Sylvester P. J., Ward B. J., Grossman L., and Hutcheon I. D. (1990) Chemical compositions of siderophile element-rich opaque assemblages in an Allende inclusion. Geochim. Cosmochim. Acta 54, 3491-3508.

Teshima J. and Larimer J. W. (1983) The IVB iron meteorite parent body: Inferences based on inclusion mineralogy and composition. Meteoritics 18, 406-407.

Ulff-Møller F. (1998) Effects of liquid immiscibility on trace element fractionation in magmatic iron meteorites: A case study of group IIIAB. Meteorit. Planet. Sci. 33, 207-220.

Wai C. M. and Wasson J. T. (1979) Nebular condensation of Ga, Ge and Sb and the chemical classification of iron meteorites. Nature 282, 790-793.

Wasson J. T. (1995) Sampling the asteroid belt: How biases make it difficult to establish meteorite-asteroid connections. Meteoritics 30, 595. 
Wasson J. T. (1999) Trapped melt in IIIAB irons; solid/liquid elemental partitioning during the fractionation of the IIIAB magma. Geochim. Cosmochim. Acta 63, 2875-2889.

Wasson J. T. and Richardson J. W. (2001) Fractionation trends among IVA iron meteorites: Contrasts with IIIAB trends. Geochim. Cosmochim. Acta 65, 951-970.

Wasson J. T., Ouyang X., Wang J. and Jerde E. (1989) Chemical classification of iron meteorites: XI. Multi-element studies of 38 new irons and the high abundance of ungrouped irons from Antarctica. Geochim. Cosmochim. Acta 53, 735-744.

Wetherill G. W. (1964) Isotopic composition and concentration of molybdenum in iron meteorites. J. Geophys. Res. 69, 4403-4408.

Willis J. and Goldstein J. I. (1982) The effects of C, P, and S on trace element partitioning during solidification in Fe-Ni alloys. J. Geophys. Res. 87, A435-A445. 


\section{FIGURE CAPTIONS}

Figure 1. LA-ICP-MS measurements of siderophile element abundances in IVB iron meteorites. Data are normalized to Ni and CI chondrites (Anders and Grevesse, 1989) and ordered by volatility (Kelly and Larimer, 1977; Wai and Wasson, 1979).

Figure 2. IVB iron meteorite compositions, plotted against Au. Solid diamonds: LA-ICPMS data, this study; open squares: NAA data, Rasmussen et al. (1984); shaded squares: NAA data, Schaudy et al. (1972); open circles: Goldberg et al. (1951), Lovering et al. (1957), Wetherill (1964), Nichiporuk and Brown (1965), Smales et al. (1967), Herpers et al. (1969), Moore et al. (1969), and Buchwald (1975). Lines: fractional crystallization model fit to the data (see text).

Figure 3. LA-ICP-MS data of Re, Os, and Pt vs. Ir illustrating good correlation between refractory siderophile elements in IVB iron meteorites.

Figure 4. Relationship between partition coefficients, using $\mathrm{D}(\mathrm{P})$ vs. $\mathrm{D}(\mathrm{Ni})$ as an example. The heavy solid line indicates the relationship between $\mathrm{D}(\mathrm{P})$ and $\mathrm{D}(\mathrm{Ni})$ that is derived from the IVB iron meteorite data (Eqn. 2); the heavy dashed line indicates its $1 \sigma$ error. Fixing $\mathrm{D}(\mathrm{P})=0.095$ according to the experimental partitioning data (Willis and Goldstein, 1982) constrains $\mathrm{D}(\mathrm{Ni})$ to $0.924 \pm 0.015$. By applying an experimental constraint from a strongly incompatible element such as $\mathrm{P}$, the propagated uncertainty on other $\mathrm{D}(x)$ is minimized.

Figure 5. Iridium vs. Ni plots illustrating the compositional trajectories of crystallizing solid in two fractional crystallization models, in which the first solid to crystallize from the melt was assumed to be either a) $15.5 \mathrm{wt} \% \mathrm{Ni}$, or b) $14.9 \mathrm{wt} \% \mathrm{Ni}$. Values of $f$, the fraction of the 
system that is crystallized, are indicated along the trajectories. Solid diamonds: LA-ICP-MS data from IVB iron meteorites.

Figure 6. Siderophile element abundances in the parent melt of the IVB iron meteorites, determined from fractional crystallization modelling of the LA-ICP-MS data. Abundances are normalized to $\mathrm{Ni}$ and $\mathrm{CI}$ chondrites (Anders and Grevesse, 1989), and ordered according to their volatility. Modest differences are observed between the preferred model (heavy line: $\mathrm{C}_{\text {initial }}(\mathrm{Ni})=15.5 \mathrm{wt} \%$ ), the model biased toward $f \geq 0.50$ introduced in Figure 5 (thin line: $\mathrm{C}_{\text {intial }}(\mathrm{Ni})=14.9 \mathrm{wt} \%$ ), and a limiting case producing $f=0.00$ for the earliestcrystallizing IVB iron (dotted line: $\left.\mathrm{C}_{\text {initial }}(\mathrm{Ni})=15.7 \mathrm{wt} \%\right)$.

Figure 7. Estimated composition of the silicate portion of the IVB parent body. The compositional range (shaded, bounded by heavy lines) was calculated assuming that the silicate fraction of the IVB parent body underwent a similar chemical history to its metal, as interpreted from the IVB iron meteorite compositions: a volatile-depleted CI chondrite composition was enriched in refractory elements by $2-5 \times$, and $28 \%$ of the Fe was sequestered into the metallic core. Depletions of the volatile lithophile elements were estimated from depletions of siderophile elements of similar volatility in IVB irons (Figure 6). Shown for comparison are whole rock compositions from four angrites (open squares; Mittlefehldt et al., 1998), and estimated angrite parent body abundances (shaded triangles) following the model of Longhi (1999), who also invoked volatile depletions but did not provide quantitative estimates for them. The $\mathrm{K}$ depletion is calculated from Angra dos Reis (Humayun and Clayton, 1995). 


\begin{tabular}{lrl}
\hline \multicolumn{2}{l}{ Table 1. Standards used for LA-ICP-MS analyses. Values in ppm except where otherwise noted. } \\
& Value & Standard \\
\hline & & \\
$\mathrm{P}$ & 290 & NIST SRM 1263a (certified value) \\
$\mathrm{V}$ & 3100 & NIST SRM 1263a (certified value) \\
$\mathrm{Cr}$ & 68 & Filomena IIAB (Wasson et al., 1989) \\
$\mathrm{Co}$ & 7800 & Hoba IVB (Campbell and Humayun, 1999b) \\
$\mathrm{Ni}$, wt\% & 16.39 & Hoba IVB (Campbell and Humayun, 1999b) \\
$\mathrm{Cu}$ & 134 & Filomena IIAB (Wasson et al., 1989) \\
$\mathrm{Ga}$ & 58.8 & Filomena IIAB (Wasson et al., 1989) \\
$\mathrm{Ge}$ & 177 & Filomena IIAB (Wasson et al., 1989) \\
$\mathrm{As}$ & 4.73 & Filomena IIAB (Wasson et al., 1989) \\
$\mathrm{Mo}$ & 300 & NIST SRM 1263a (certified value) \\
$\mathrm{Ru}$ & 28.61 & Hoba IVB (Campbell and Humayun, 1999b) \\
$\mathrm{Rh}$ & 4.86 & Hoba IVB (Campbell and Humayun, 1999b) \\
$\mathrm{Pd}$ & 6.65 & Hoba IVB (Campbell and Humayun, 1999b) \\
$\mathrm{W}$ & 2.56 & Filomena IIAB (Wasson et al., 1989) \\
$\mathrm{Re}$ & 3.15 & Hoba IVB (Campbell and Humayun, 1999b) \\
$\mathrm{Os}$ & 42.48 & Hoba IVB (Campbell and Humayun, 1999b) \\
$\mathrm{Ir}$ & 29.14 & Hoba IVB (Campbell and Humayun, 1999b) \\
$\mathrm{Pt}$ & 28.60 & Hoba IVB (Campbell and Humayun, 1999b) \\
$\mathrm{Au}$ & 0.612 & Filomena IIAB (Wasson et al., 1989) \\
\hline
\end{tabular}


Table 2. LA-ICP-MS measurements of IVB iron meteorites. Data in ppm except where indicated. Errors are 1 $\sigma$. Underlined entries are detection limits.

\begin{tabular}{|c|c|c|c|c|c|c|c|}
\hline & Cape of Good Hope & Tlacotepec & Hoba & Santa Clara & Skookum & Tawallah Valley & Warburton Range \\
\hline$P$ & $445 \pm 13$ & $472 \pm 18$ & $757 \pm 27$ & $1250 \pm 113$ & $2019 \pm 469$ & $1762 \pm 377$ & $1950 \pm 206$ \\
\hline V & $0.95 \pm 0.04$ & $0.37 \pm 0.04$ & $1.08 \pm 0.34$ & $0.05 \pm 0.01$ & $0.37 \pm 0.08$ & $0.09 \pm 0.01$ & $0.22 \pm 0.03$ \\
\hline $\mathrm{Cr}$ & $261 \pm 20$ & $159 \pm 13$ & $178 \pm 14$ & $76 \pm 7$ & $36 \pm 3$ & $69 \pm 5$ & $76 \pm 6$ \\
\hline Co & $7820 \pm 30$ & $7687 \pm 90$ & $7807 \pm 14$ & $7797 \pm 55$ & $7912 \pm 55$ & $8158 \pm 41$ & $8021 \pm 47$ \\
\hline $\mathrm{Ni}, \mathrm{wt} \%$ & $15.64 \pm 0.16$ & $15.60 \pm 0.17$ & $16.33 \pm 0.10$ & $17.19 \pm 0.20$ & $17.43 \pm 0.19$ & $17.94 \pm 0.24$ & $18.02 \pm 0.32$ \\
\hline $\mathrm{Cu}$ & $1.48 \pm 0.06$ & $1.29 \pm 0.03$ & $1.62 \pm 0.07$ & $1.54 \pm 0.06$ & $1.89 \pm 0.02$ & $1.87 \pm 0.05$ & $2.08 \pm 0.05$ \\
\hline $\mathrm{Ga}$ & $0.151 \pm 0.009$ & $0.156 \pm 0.010$ & $0.148 \pm 0.011$ & $0.201 \pm 0.012$ & $0.222 \pm 0.014$ & $0.198 \pm 0.012$ & $0.225 \pm 0.014$ \\
\hline $\mathrm{Ge}$ & $0.050 \pm 0.005$ & $0.051 \pm 0.005$ & $0.059 \pm 0.009$ & $0.065 \pm 0.008$ & $0.080 \pm 0.006$ & $0.075 \pm 0.006$ & $0.100 \pm 0.007$ \\
\hline As & $\underline{0.19}$ & $0.21 \pm 0.04$ & $0.48 \pm 0.09$ & $0.73 \pm 0.03$ & $1.03 \pm 0.09$ & $0.89 \pm 0.05$ & $0.88 \pm 0.05$ \\
\hline Mo & $25 \pm 2$ & $25 \pm 2$ & $26 \pm 2$ & $33 \pm 2$ & $37 \pm 3$ & $37 \pm 3$ & $42 \pm 3$ \\
\hline $\mathrm{Ru}$ & $31.4 \pm 0.7$ & $29.9 \pm 0.7$ & $28.5 \pm 0.6$ & $25.5 \pm 0.7$ & $23.2 \pm 0.9$ & $23.0 \pm 0.9$ & $23.8 \pm 0.6$ \\
\hline $\mathrm{Rh}$ & $4.87 \pm 0.11$ & $4.82 \pm 0.11$ & $4.81 \pm 0.10$ & $5.06 \pm 0.13$ & $4.84 \pm 0.16$ & $4.97 \pm 0.18$ & $5.23 \pm 0.11$ \\
\hline $\mathrm{Pd}$ & $6.10 \pm 0.17$ & $6.38 \pm 0.16$ & $6.67 \pm 0.11$ & $9.01 \pm 0.27$ & $9.88 \pm 0.26$ & $10.71 \pm 0.23$ & $11.34 \pm 0.24$ \\
\hline W & $3.49 \pm 0.05$ & $3.45 \pm 0.10$ & $3.25 \pm 0.05$ & $3.42 \pm 0.04$ & $3.16 \pm 0.07$ & $3.27 \pm 0.10$ & $3.77 \pm 0.12$ \\
\hline $\operatorname{Re}$ & $3.96 \pm 0.10$ & $3.66 \pm 0.05$ & $3.13 \pm 0.04$ & $2.13 \pm 0.03$ & $1.59 \pm 0.03$ & $1.59 \pm 0.04$ & $1.52 \pm 0.02$ \\
\hline Os & $55.0 \pm 1.5$ & $50.6 \pm 1.5$ & $41.9 \pm 1.3$ & $25.9 \pm 0.8$ & $18.7 \pm 0.7$ & $18.3 \pm 0.7$ & $17.4 \pm 0.5$ \\
\hline Ir & $35.4 \pm 1.5$ & $33.3 \pm 1.5$ & $29.0 \pm 1.3$ & $21.8 \pm 1.0$ & $17.0 \pm 0.9$ & $16.9 \pm 0.9$ & $16.4 \pm 0.7$ \\
\hline $\mathrm{Pt}$ & $29.6 \pm 1.2$ & $29.0 \pm 1.2$ & $28.6 \pm 1.2$ & $30.0 \pm 1.3$ & $28.4 \pm 1.3$ & $29.9 \pm 1.4$ & $31.1 \pm 1.2$ \\
\hline $\mathrm{Au}$ & $0.059 \pm 0.002$ & $0.059 \pm 0.002$ & $0.078 \pm 0.003$ & $0.127 \pm 0.004$ & $0.142 \pm 0.003$ & $0.152 \pm 0.004$ & $0.174 \pm 0.004$ \\
\hline
\end{tabular}


Table 3. Partition coefficients (D) and initial compositions $\left(\mathrm{C}_{0}\right)$ from fractional crystallization modelling of the IVB parent melt.

\begin{tabular}{|c|c|c|c|c|}
\hline & $\mathrm{C}_{0}$ & $\mathrm{D}$ & $D(\text { lit. })^{\mathrm{a}}$ & D (exp.) \\
\hline$P$ & 0.40 wt $\%$ & 0.095 & & $0.09^{b}, 0.065^{d}$ \\
\hline $\mathrm{Cr}$ & 130 ppm & $1.92 \pm 0.10$ & 1.49 & $0.51^{\mathrm{b}}$ \\
\hline Co & 0.790 wt $\%$ & $0.980 \pm 0.007$ & 0.977 & $0.97^{b}, 1.0^{d}$ \\
\hline $\mathrm{Ni}$ & 16.8 wt $\%$ & $0.924 \pm 0.015$ & 0.950 & $0.90^{b}, 0.87^{d}$ \\
\hline $\mathrm{Cu}$ & 1.64 ppm & $0.77 \pm 0.03$ & $\sim 1.0$ & $0.87^{e}$ \\
\hline $\mathrm{Ga}$ & 0.183 ppm & $0.77 \pm 0.08$ & 0.86 & $0.83^{b}, 0.96^{c}, 0.84^{d}$ \\
\hline $\mathrm{Ge}$ & $0.068 \mathrm{ppm}$ & $0.68 \pm 0.11$ & $\sim 0.80$ & $0.58^{b}, 0.68^{c}, 0.71^{d}$ \\
\hline As & $0.81 \mathrm{ppm}$ & $0.33 \pm 0.20$ & 0.40 & $0.23^{d}$ \\
\hline Mo & 32 ppm & $0.72 \pm 0.09$ & & \\
\hline $\mathrm{Ru}$ & $27.4 \mathrm{ppm}$ & $1.16 \pm 0.03$ & & \\
\hline $\mathrm{Rh}$ & 4.96 ppm & $0.97 \pm 0.03$ & & \\
\hline $\mathrm{Pd}$ & $8.6 \mathrm{ppm}$ & $0.64 \pm 0.03$ & & $0.44^{d}$ \\
\hline W & $3.39 \mathrm{ppm}$ & $1.01 \pm 0.03$ & $\sim 1.0$ & $1.3^{\mathrm{d}}$ \\
\hline $\operatorname{Re}$ & $2.8 \mathrm{ppm}$ & $1.55 \pm 0.02$ & 1.42 & $2.3^{d}$ \\
\hline Os & 37 ppm & $1.66 \pm 0.04$ & & $2.3^{d}$ \\
\hline Ir & 27 ppm & $1.44 \pm 0.06$ & 1.325 & $1.65^{b}, 1.76^{c}, 1.7^{d}$ \\
\hline $\mathrm{Pt}$ & 29.5 ppm & $0.98 \pm 0.05$ & & $0.91^{d}$ \\
\hline $\mathrm{Au}$ & $0.13 \mathrm{ppm}$ & $0.41 \pm 0.04$ & 0.61 & $0.27^{\mathrm{b}}, 0.44^{\mathrm{c}}, 0.26^{\mathrm{d}}$ \\
\hline \multicolumn{5}{|c|}{${ }^{a}$ Rasmussen et al. (1984) } \\
\hline \multicolumn{5}{|c|}{${ }^{\mathrm{b}}$ Calculated from Jones and Malvin (1990), Fe-Ni-S system. } \\
\hline \multicolumn{5}{|c|}{${ }^{\mathrm{C} C}$ alculated from Jones and Malvin (1990), Fe-Ni-P system. } \\
\hline \multicolumn{5}{|c|}{${ }^{\mathrm{d} C}$ Calculated from Chabot and Jones (2003). } \\
\hline \multicolumn{5}{|c|}{${ }^{\mathrm{e}}$ Calculated from data in Chabot et al. (2003). } \\
\hline
\end{tabular}




\begin{tabular}{|c|c|}
\hline Meteorite & $f$ \\
\hline Cape of Good Hope & 0.167 \\
\hline Tlacotepec & 0.259 \\
\hline Hoba & 0.461 \\
\hline Santa Clara & 0.736 \\
\hline Skookum & 0.833 \\
\hline Tawallah Valley & 0.837 \\
\hline Warburton Range & 0.856 \\
\hline
\end{tabular}




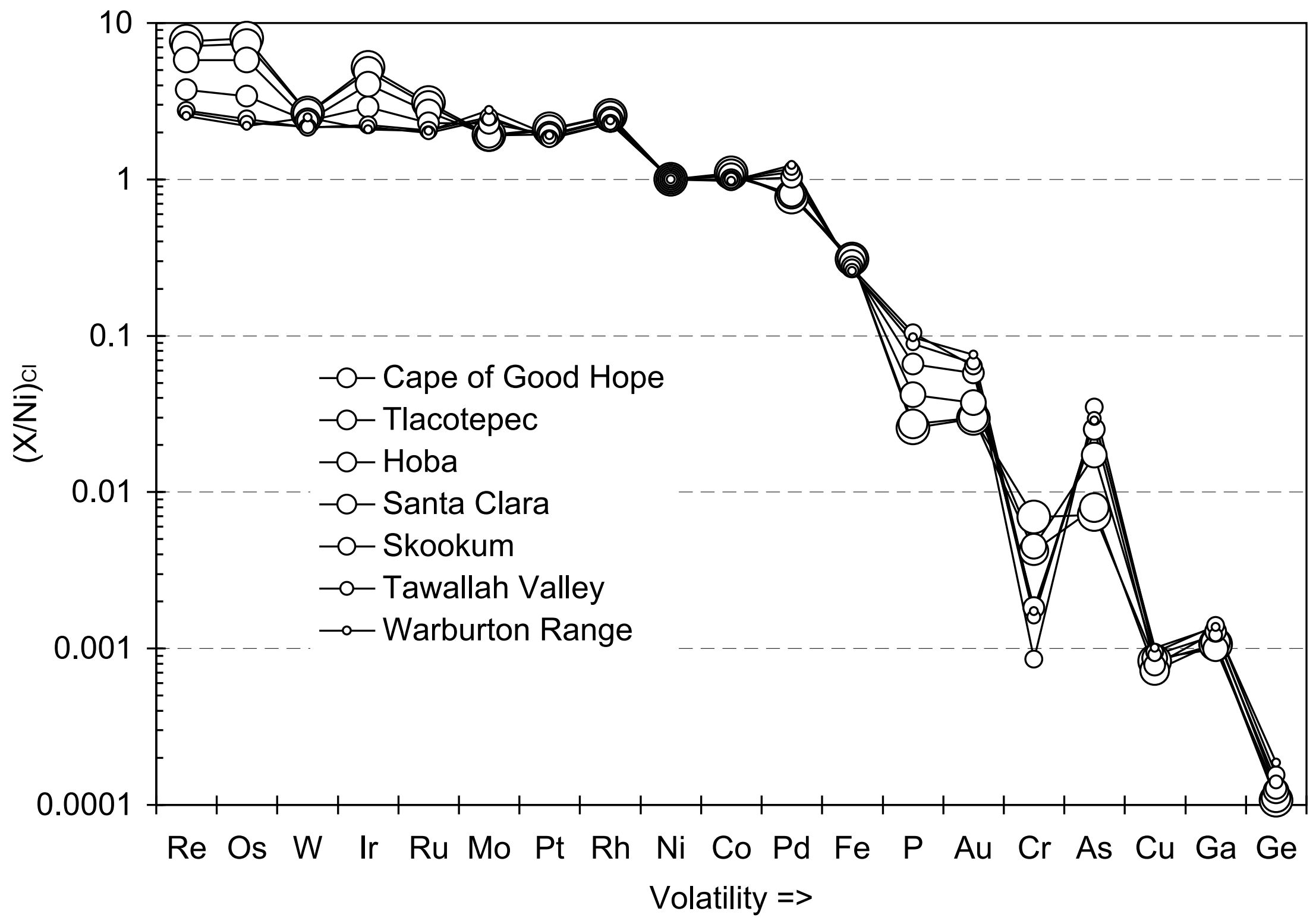

Figure 1 

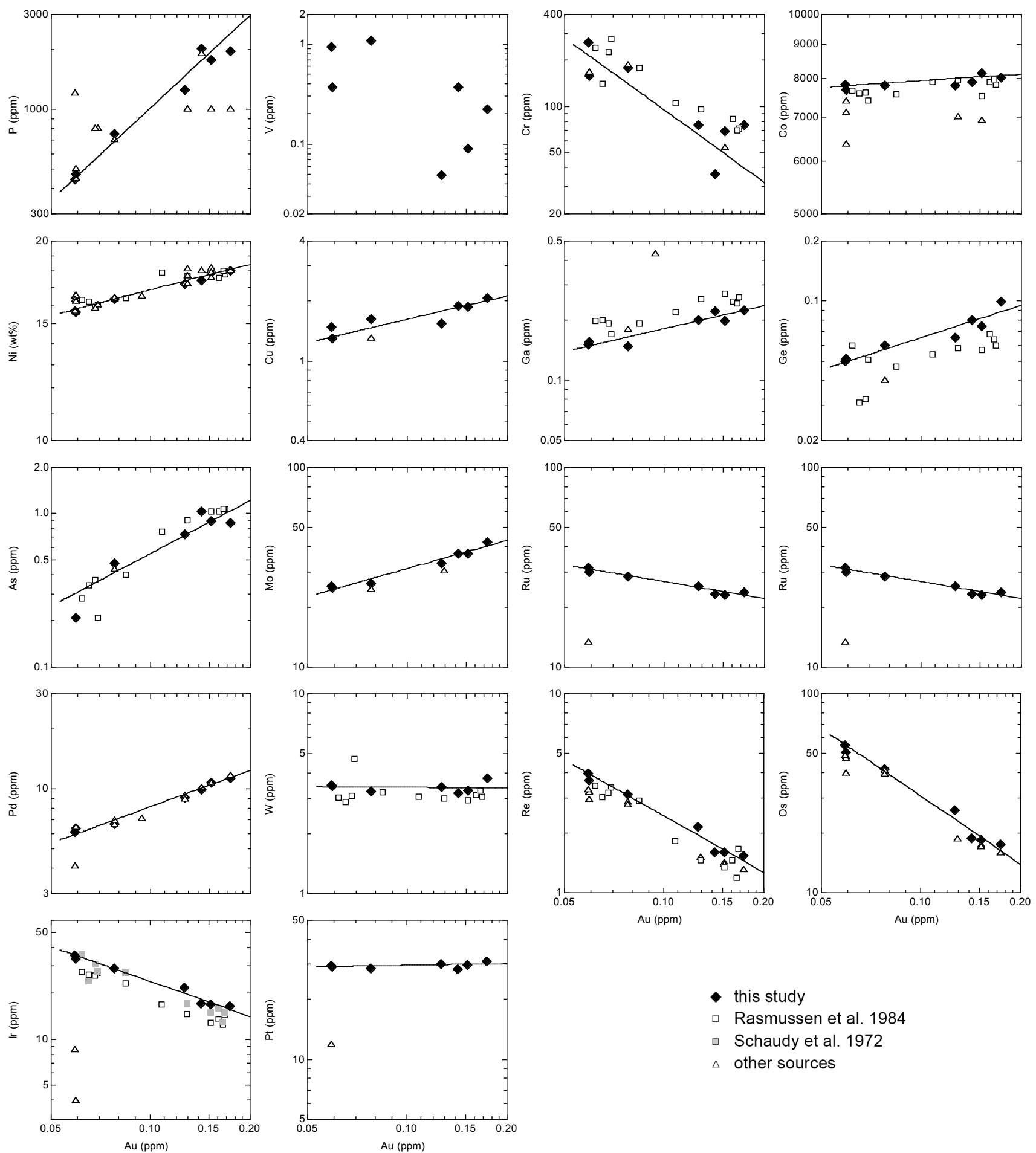

- this study

- Rasmussen et al. 1984

- Schaudy et al. 1972

$\triangle$ other sources 


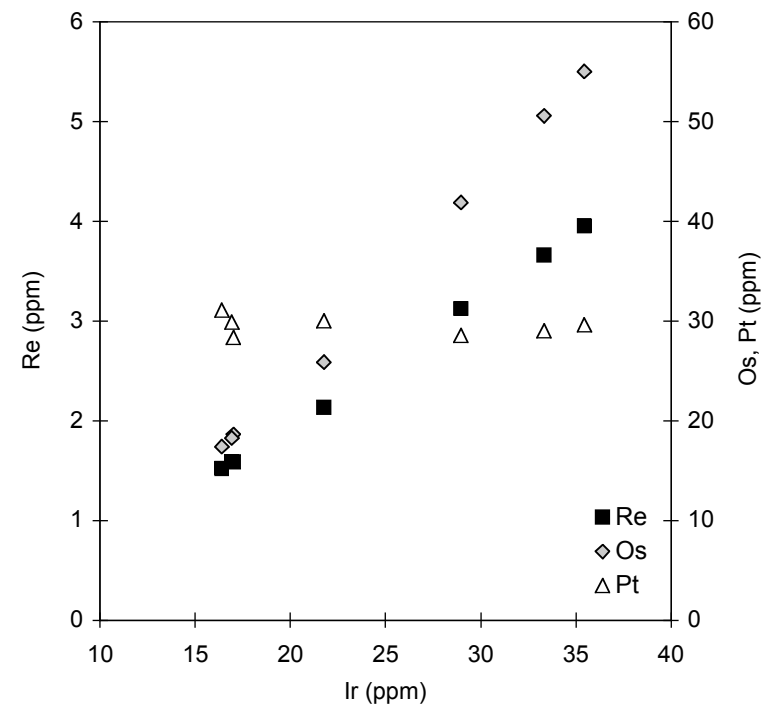

Figure 3 


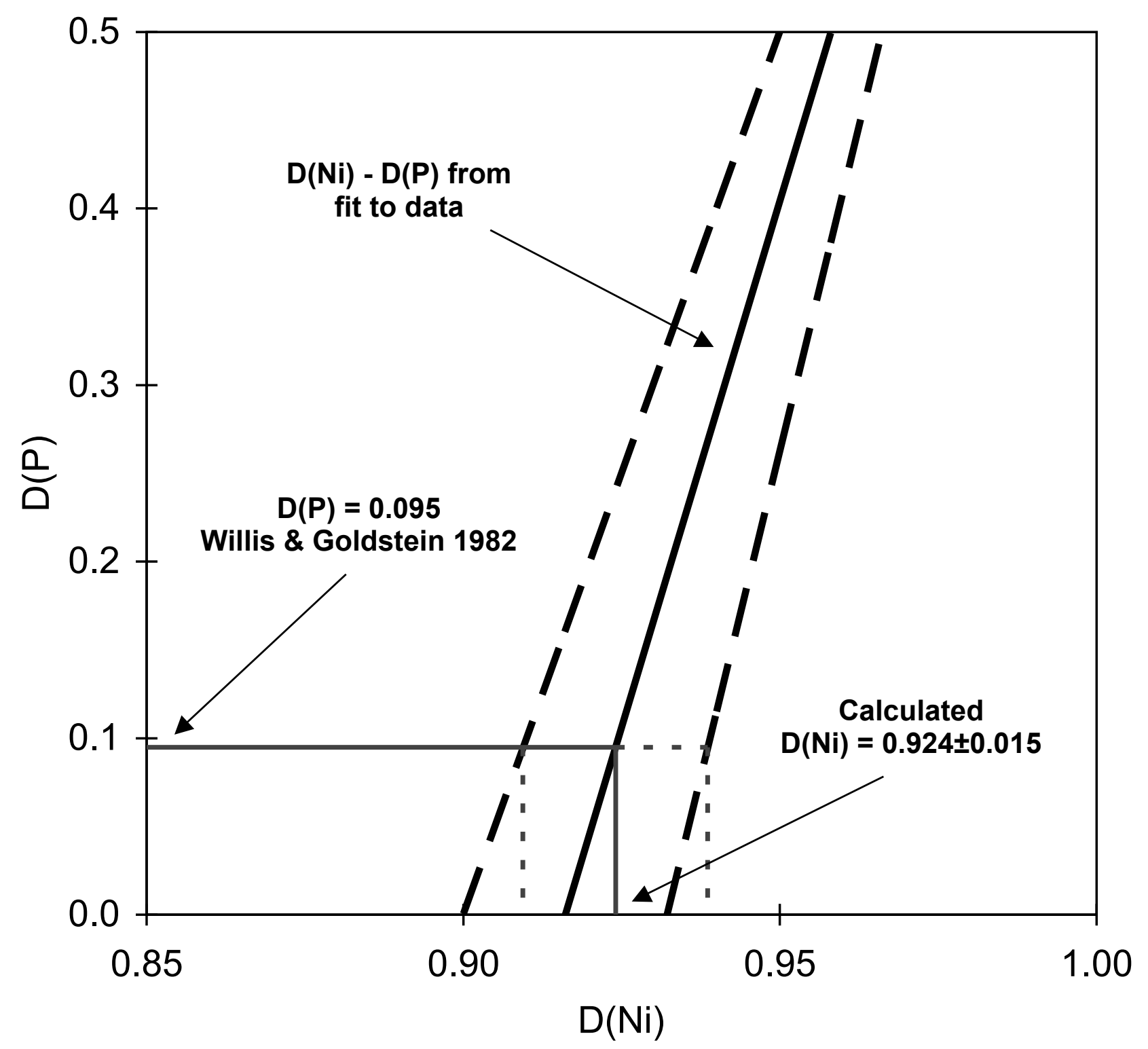

Figure 4 

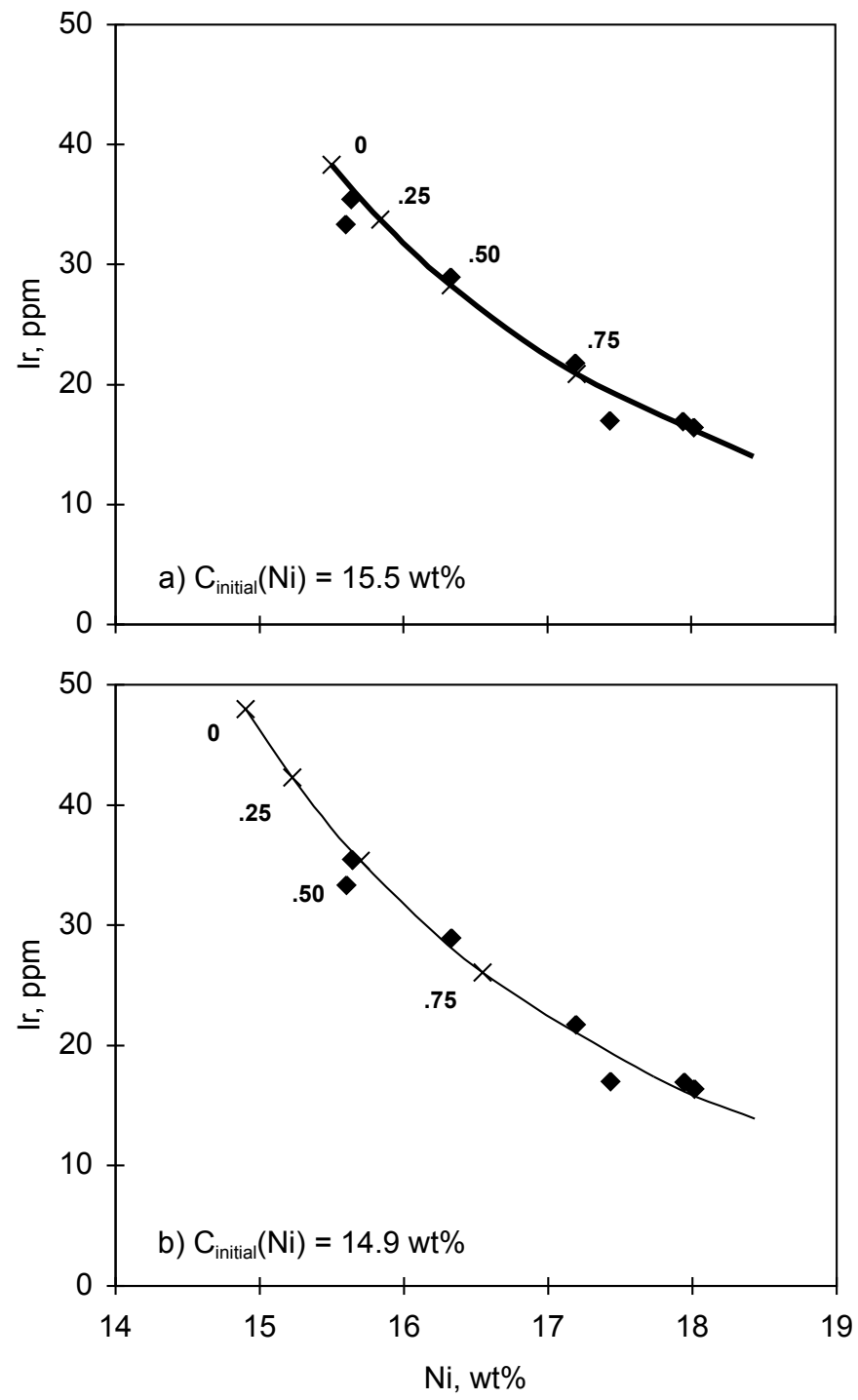

Figure 5 


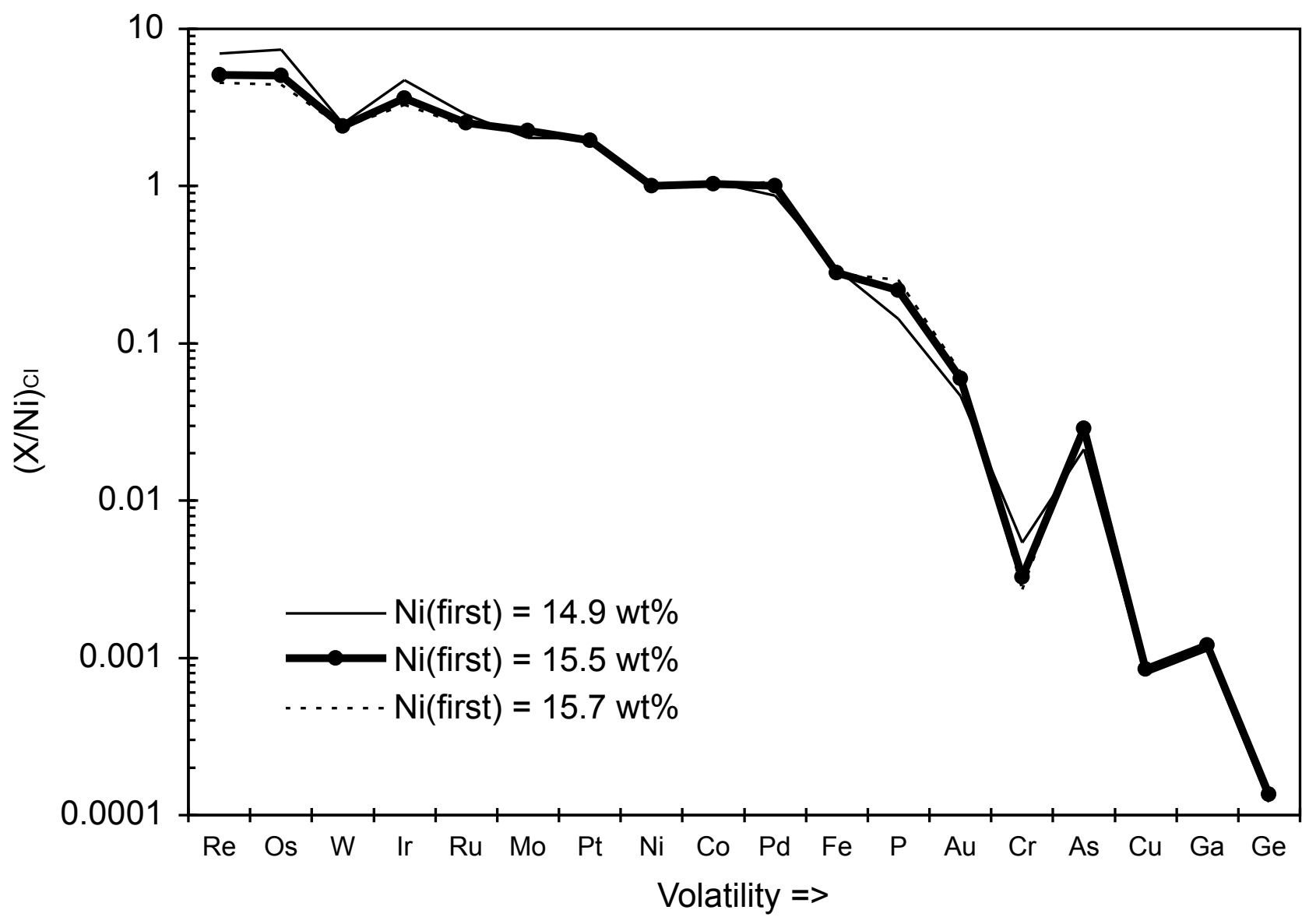

Figure 6 


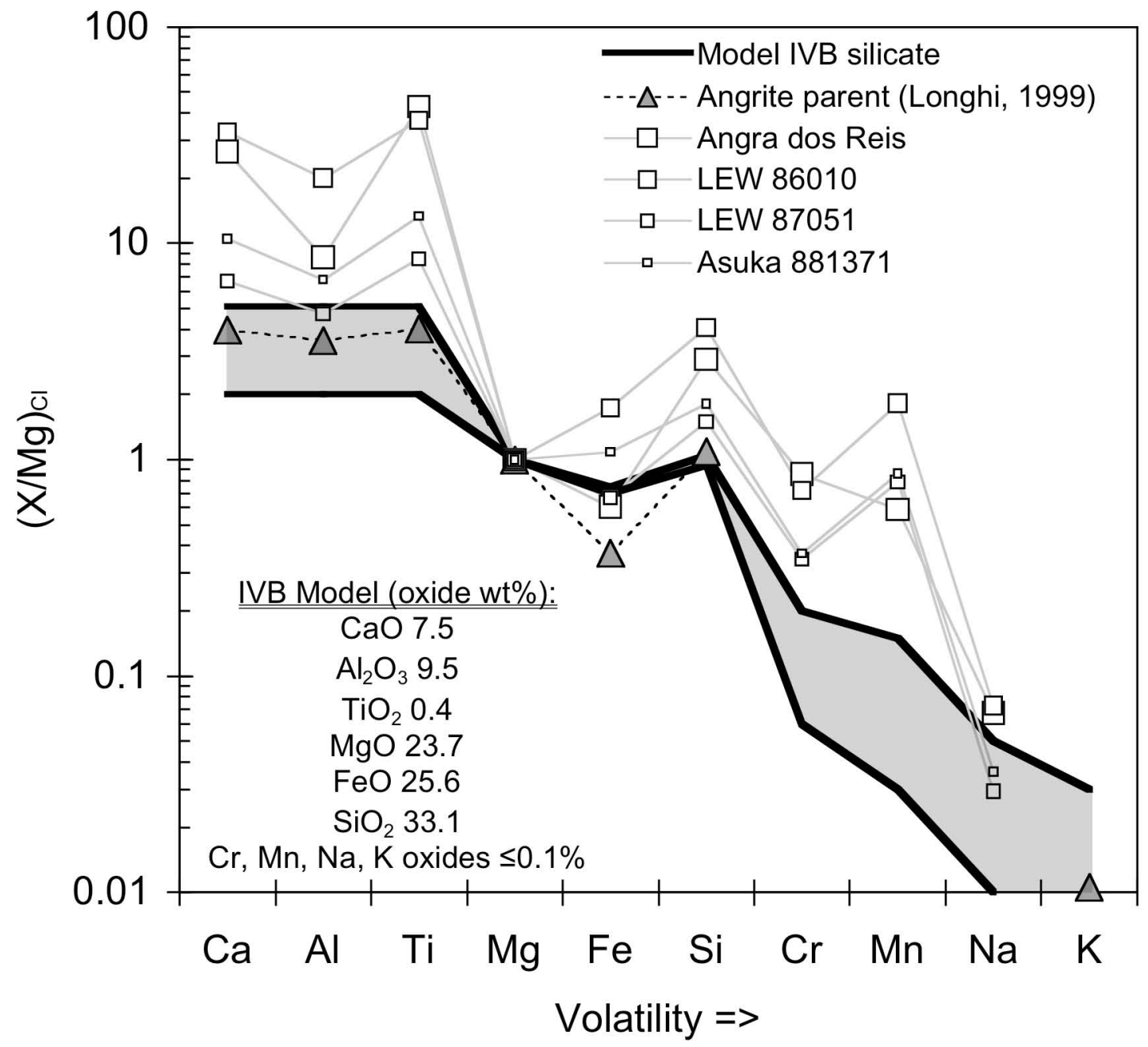

Figure 7 